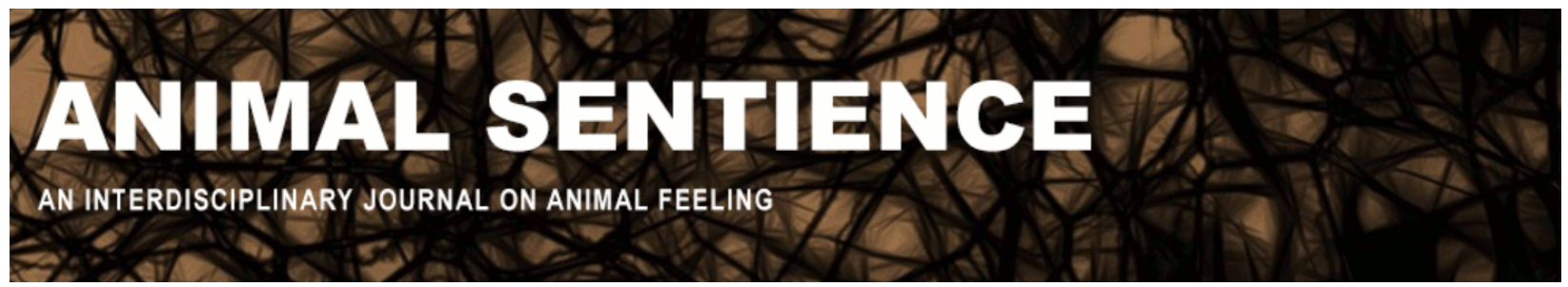

Correia Caeiro, Catia (2019) What we don't know about cephalopods and how to define it. Animal Sentience 26(22)

DOI: 10.51291/2377-7478.1509

Date of submission: 2019-07-30

Date of acceptance: 2019-08-08

(c) (†)

This article has appeared in the journal Animal

Sentience, a peer-reviewed journal on animal

cognition and feeling. It has been made open access,

free for all, by WellBeing International and deposited

in the WBI Studies Repository. For more information,

please contact

wbisr-info@wellbeingintl.org.

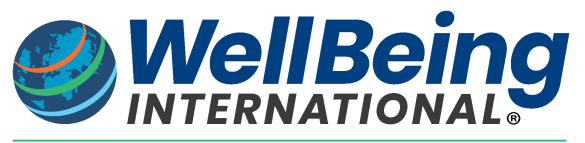

SOLUTIONS FOR PEOPLE, ANIMALS AND ENVIRONMENT 


\title{
What we don't know about cephalopods and how to define it
}

Commentary on Mather on Octopus Mind

\author{
Catia Correia Caeiro \\ School of Life Sciences \\ University of Lincoln, UK
}

\begin{abstract}
Despite the reputation of octopuses as intelligent animals, their cognitive abilities seem to be mostly unknown. This should be the starting point of a long process of scientific enquiry about these taxa, which must include discussions on operational definitions first and foremost. Discussing octopus mind might prove fruitless without more basic concepts. Some approaches are suggested here.
\end{abstract}

Catia Correia Caeiro studies the cognitive capacities of different species (e.g., primates and domestic animals), applying a comparative and evolutionary perspective. Her research focuses on communication and emotional expression in animals. Website

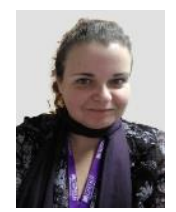

1. The unknown cephalopoda: After reading Mather's (2019) informative target article, I was surprised to learn how little we know about the cognition (and mind) of octopuses and closely related species. As a student of primate and domestic animal cognition, I was amazed at how little we know about cephalopods, a taxon with a reputation for "intelligence." I felt Mather made too many assumptions without convincing evidence, for example, the assumption that "vision does not dominate their perception as much as it does in humans." This had been assumed about dogs on the basis of their visual physiology and neuroanatomy (Warden \& Warner 1928), until behavioral research showed that canine vision is superior to humans' in some aspects (Byosiere et al. 2018). Similarly, being color blind does not necessarily represent a disadvantage, especially in an environment where color is not important, because this usually translates into better pattern detection (Saito et al. 2006). Although anecdotal and absent information are good starting points to motivate studies and inform experimental design, I would have expected a larger emphasis in Mather's target article on what we do not know and need to investigate.

2. The lack of operational definitions: Mather's article makes use of several concepts that are never defined, including mind, mindfulness, intelligence, and consciousness. The mind-brain debate is not a new one (Sperry 1952), but far from settled (Damasio 1999). Basing octopus cognition on some kind of a "mind" is at best a hard task. Like Mallat (2019), I believe an operational definition of mind for octopus is essential. In King \& Marino (2019), a definition is based on reasoning and flexible responses. Mather provides notes that the octopus mind is different from vertebrate minds. But what is it exactly?

For Siegel (2015), "mind" is intrinsically linked to (human) sociality (also mentioned by Lee 2019). But octopuses are asocial for most of their lifespans. Mind can also be defined in its 
more basic form as simply the emergent processes from brain activity. According to dualism, mental and physical phenomena would be independent (Sperry 1980). For Panksepp (2003), the brain-mind framework includes cognitive and affective aspects, at least in mammals. Damasio (1999) presents a two-part approach in which the first part of the conscious mind is based on the sensory information that builds a "movie-in-the-brain" and the second is a sense of self and ownership of the "movie."

Mather's target article did not seem to adopt any of the above definitions for octopuses; hence we need a different approach for them. Some definitions of mind include directed intentionality (Määttänen 2015). An alternative approach might be to measure degree of intentionality, which has been operationally defined to study primates (Liebal et al. 2014). Operational definitions must be established to be able to make comparisons between species.

Not only in the target article, but also in several commentaries, a variety of concepts are used interchangeably or causally related, such as consciousness, mind, sentience, intentionality, and reasoning. These not only lack scientific rigor (as noted by Schnell \& Vallortigara 2019), but moot the point of demonstrating that octopuses have a mind if a mind can be almost anything the writer wishes.

In a prior commentary on canine cognition (Caeiro 2017), I suggested that concepts need to form the basis of scientific debates and experimental studies. We should try to test whether octopuses have a mind, but using the same strict definitions that would be applied to bacteria, plants, or humans. The mind itself is not testable directly, but features of mind can be tested, such as intentionality, cognitive bias, cognitive complexity and so on. Consciousness is still a poorly understood biological phenomenon in humans and is questionable in animals (Gutfreund 2018). As noted by Guerra (2019), Schwartz (2019), and Pellis (2019), the "two brains hypothesis" does not stand up to scrutiny, for then many other animals would have two brains (the enteric nervous system, whose activity is independent from the CNS; Sasselli et al. 2012). No independent consciousness has yet been found in the stomach of any species. Intelligence too is a questionable term (see Caeiro 2019 regarding sheep cognition).

3. The emotional octopus? Just as the mind of octopuses cannot be linked to sociality, their social organisation (or lack thereof) cannot be used as evidence of underlying emotional systems. A distinction needs to be made between emotional systems and motivational systems, which are conflated to some extent in the target article. In mammals, emotional systems are well studied; exploration, mentioned by Mather, takes place when the brain system underlying search is activated. Do octopuses have an equivalent system? If we assume octopuses have a mind according to Panksepp's framework, does this also mean they have affective processes?

It is known that octopuses have some neurochemicals similar to those of humans, such as serotonin (Edsinger \& Dölen 2018), oxytocin and vasopressin (Kanda, Satake, Kawanda, \& Minakata 2005, cited also by Aitken 2019). These are well known to be important for positive emotions in humans (e.g., Young 2007). Tests on cognitive bias in octopuses or further studies on the neurochemistry of the brains in this might shed light on both cognitive and affective aspects of the octopus mind.

Other than the search and fear systems mentioned by Mather and Browning (2019), is there evidence for other systems in octopuses (sensu Panksepp 2011) that might be relevant to their welfare, in that they can cause potential suffering? As other commentators have suggested 
(e.g., Lee 2019), having a mind is not so relevant for octopus welfare (or even for the study of their cognition); what matters is whether they can they feel, whether they can suffer. This question can be taken further, as cognition is not important without affective qualities (e.g., Artificial Intelligence can perform impressive tasks with comparably high cognitive abilities).

4. Conclusion: In order to talk about minds in octopuses, we must go back to what was defined as a mind for humans. It is a mystery why octopuses have such advanced cognitive abilities, since the variables usually highly correlated with higher order cognition seem to be absent, such as sociality. The future directions of study in this taxon should instead focus on trying to understand not only what their cognitive abilities are, but why they are so developed. Predatory pressures or changeable environment alone (Mather 2019, Aitken 2019) cannot explain their cognitive abilities, so something else must be up. The question is not whether we should say octopuses have minds (as Gutfreund 2019 does), but what is the evidence for it? As Vonk (2019) points out, even if they do not have a mind, they are still of scientific interest. Not having a mind, does not exclude advanced cognition. Or, as Mehrkham (2019) says, there is no need for mind to see they are complex learners and worthy of welfare consideration (King \& Marino 2019). Mather does a great job summarising some of the important information to allow us to conclude this. However, the fulcral point, the definition of mind (and other concepts), is absent.

\section{References}

Aitken, K. J. (2019). Are our ideas about octopus life too anthropomorphic to help? Animal Sentience 26(11)

Bohórquez, D. V., \& Liddle, R. A. (2015). The gut connectome: Making sense of what you eat. The Journal of Clinical Investigation, 125(3), 888-890.

Browning, H. (2019). What is good for an octopus? Animal Sentience 26(7)

Byosiere, S. E., Chouinard, P. A., Howell, T. J., \& Bennett, P. C. (2018). What do dogs (Canis familiaris) see? A review of vision in dogs and implications for cognition research. Psychonomic Bulletin \& Review, 25(5), 1798-1813.

Damasio, A. R. (1999). How the brain creates the mind. Scientific American, 281(6), 112-117.

Edsinger, E., \& Dölen, G. (2018). A conserved role for serotonergic neurotransmission in mediating social behavior in octopus. Current Biology, 28(19), 3136-3142.

Guerra, A. (2019). The ingenuity of cephalopods. Animal Sentience 26(5)

Gutfreund, Y. (2018). The mind-evolution problem: The difficulty of fitting consciousness in an evolutionary framework. Frontiers in Psychology, 9, 1537.

Gutfreund, Y. (2019). Who needs a mind when you have thousands of fingers? Animal Sentience 26(3)

King, B. J., \& Marino, L. (2019). Octopus minds must lead to octopus ethics. Animal Sentience 26(14)

Lee, P. C. (2019). Are octopuses special? Mind, sociality and life history. Animal Sentience 26(10)

Liebal, K., Waller, B. M., Slocombe, K. E., \& Burrows, A. M. (2014). Primate communication: A multimodal approach. Cambridge University Press.

Määttänen, P. (2015). Mind and interaction. Mind in Action, 53-66. 
Mallat, J. (2019). The octopus: A beautiful (but disorganized) "mind". Animal Sentience 26(8) Mather, J. (2019). What is in an octopus's mind? Animal Sentience 26(1) Mehrkam, L. R. (2019). A behavior-analytic approach to understanding octopus "mind". Animal Sentience 26(12)

Panksepp, J. (2003). At the interface of the affective, behavioral, and cognitive neurosciences: Decoding the emotional feelings of the brain. Brain and Cognition, 52(1), 4-14.

Panksepp, J. (2011). The basic emotional circuits of mammalian brains: Do animals have affective lives?. Neuroscience \& Biobehavioral Reviews, 35(9), 1791-1804.

Pellis, S. M. (2019). The 'Thing' from this world. Animal Sentience 26(9)

Saito, A., Mikami, A., Hosokawa, T., \& Hasegawa, T. (2006). Advantage of dichromats over trichromats in discrimination of color-camouflaged stimuli in humans. Perceptual and Motor Skills, 102(1), 3-12.

Sasselli, V., Pachnis, V., \& Burns, A. J. (2012). The enteric nervous system. Developmental Biology, 366(1), 64-73.

Schnell, A., \& Vallortigara, G. (2019). 'Mind' is an ill-defined concept: Considerations for future cephalopod research. Animal Sentience 26(16)

Schwartz, B. L. (2019). A community of minds. Animal Sentience 26(4)

Siegel, D. J. (2015). The developing mind: How relationships and the brain interact to shape who we are. Guilford Publications.

Sperry, R. W. (1952). Neurology and the mind-brain problem. American Scientist, 40(2).

Sperry, R. W. (1980). Mind-brain interaction - Mentalism, yes; dualism, no. Neuroscience, 5(2), 195-206.

Vonk, J. (2019). Octopi-ing a unique niche in comparative psychology. Animal Sentience 26(6)

Warden, C. J., \& Warner, L. H. (1928). The sensory capacities and intelligence of dogs, with a report on the ability of the noted dog "Fellow" to respond to verbal stimuli. The Quarterly Review of Biology, 3(1), 1-28.

Young, S. N. (2007). How to increase serotonin in the human brain without drugs. Journal of Psychiatry \& Neuroscience: JPN, 32(6), 394. 